\title{
Taming the lion: the challenge of immunity in regenerative medicine
}

\author{
"...the immune system represents a formidable opponent for regenerative medicine \\ that we ignore at our peril."
}

\begin{abstract}
Keywords: dendritic cells $\bullet$ graft versus host disease $\bullet$ hematopoietic stem cell transplantation $\bullet$ immune suppression $\bullet$ immunogenicity $\bullet$ mesenchymal stem cells $\bullet$ pluripotent stem cells $\bullet$ thymic involution
\end{abstract}

When invited to serve as guest editor for this Special Focus Issue of Regenerative Medicine, I felt deeply honored yet somehow daunted by the task. Having begun my scientific career as a card-carrying immunologist, with a particular interest in whole organ transplantation, I frequently receive invitations to speak at stem cell conferences where I am invariably given the remit of discussing the risks of rejection and prospects for its mitigation in the context of cell replacement therapy. But the news is neither good nor welcome: indeed my lasting impression of such occasions is that I have single handedly spoilt an otherwise vibrant party! Because, whether we like it or not, there seems little doubt that the immune system represents a formidable opponent for regenerative medicine that we ignore at our peril. Indeed, many decades of research into whole organ transplantation have done little to wean us off a long-term dependence on immune suppression. And yet such a solution to the problem may be contraindicated for many stem cell therapies, especially those based on the use of pluripotent stem cells for which the risks of tumorigenesis are uncompromisingly high: to suppress the immune system while administering cells with a proven propensity for transformation would doubtless expose recipients to unacceptable levels of risk. But while the challenges posed by the immune system should never be underestimated, there are also reasons for hope. There is little doubt, for instance, that tapping into the properties of pluripotency offers unparal- leled opportunities in the field of immunotherapy. Indeed, accessing rare cell types of immunological significance through the directed differentiation of pluripotent stem cells, may provide a welcome new paradigm for addressing various unmet medical needs with an underlying immunological basis: it is these emerging opportunities, as well as the inevitable challenges that face the sector, that we have sought to reflect in the articles we have invited from authors, renowned in their respective fields.

The potential for immunological rejection to derail the likely future benefits of regenerative medicine has been appreciated for many years. The need to deal comprehensively with such a threat was amply reflected in the UK Government's 2012 Strategy for UK Regenerative Medicine, in response to which the UK Regenerative Medicine Platform (UKRMP) was founded. The recent establishment of an Immunomodulation Hub as part of this initiative is, therefore, to be welcomed. The nascent hub is outlined in our Organizational Profile, which features an interview with Co-Director, Francesco Dazzi [1] and details of contributions from the various partners in the consortium [2]. The importance of addressing the immunological constraints of stem cell therapies from a pharmaceutical perspective is discussed by Richard Haworth and Michaela Sharpe, who outline how the immune response poses a significant risk factor to the development of novel cell therapies, greatly complicating their progress to market [3]. They advocate the need for assays to

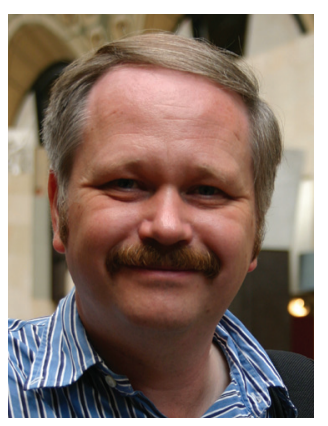

Paul J Fairchild University of Oxford, Sir William Dunn School of Pathology, South Parks Road, Oxford, OX1 3RE, UK paul.fairchild@path.ox.ac.uk 
conclusions, questioning the universal utility of mesenchymal stem cells as an immunosuppressive regime [9]. In contrast, Noga Or-Geva and Yair Reisner outline a novel approach to reducing GVHD based on exploiting the so-called veto activity of $\mathrm{CD}^{+}$central memory $\mathrm{T}$ cells activated to third party alloantigens, a strategy that may facilitate early engraftment with minimal GVHD while potentially preserving the beneficial graft-versus-tumor effect [10].

Although regenerative medicine continues to pose many immunological challenges, it has also provided numerous opportunities to intervene in a variety of disease states with an underlying immunological basis. In our Perspective article, members of my own laboratory review recent advances in the generation of dendritic cell subsets from human pluripotent stem cells [11]. Such a novel source may address many of the current limitations to the use of dendritic cells derived from peripheral blood monocytes and provide a platform for vaccination to tumor-associated antigens and chronic infectious microorganisms, as well as the induction of tolerance to defined protein antigens. Furthermore, Nicholas Bredenkamp and colleagues describe exciting advances in the regeneration of a functioning thymus in old age through exploitation of pluripotent stem cells or the direct reprogramming of fibroblasts to thymic epithelial cells [12]. Such advances may one day permit the reversal of age-related thymic involution, which currently impedes reconstitution of the $\mathrm{T}$-cell repertoire following depletion of $\mathrm{T}$ cells in the

\section{References}

1 Dazzi F. The UKRMP Immunomodulation Hub. Regen. Med. 10(3), 255-257 (2015).

2 Asante C, Ali R, Dazzi F et al. Organizational profile: UKRMP Immunomodulation Hub. Regen. Med. 10(3), 259-263 (2015).

3 Haworth R, Sharpe M. The issue of immunology in stem cell therapies: a pharmaceutical perspective. Regen. Med. 10(3), 231-234 (2015).

4 Roberton VH, Rosser AE, Kelly CM. Neonatal desensitisation for the study of regenerative medicine. Regen. Med. 10(3), 265-274 (2015).

5 Wilmut I, Leslie S, Nicholas G et al. Development of a global network of induced pluripotent stem cell haplobanks. Regen. Med. 10(3), 235-238 (2015).

6 Bolton EM, Bradley JA. Avoiding immunological rejection in regenerative medicine. Regen. Med. 10(3), 287-304 (2015).

7 Vertès AA. The potential of cytotherapeutics in hematologic reconstitution and in the treatment and prophylaxis of graft-versus-host disease. Chapter I: Current practice and remaining unmet medical needs. Regen. Med. 10(3), 331-343 (2015). periphery due to chemotherapy or chronic infectious agents, such as HIV-1.

\section{"...tapping into the properties of pluripotency offers unparalleled opportunities in the field of immunotherapy."}

There is little doubt that the immunology of regenerative medicine remains an immature discipline that lags significantly behind the basic science underlying the generation and differentiation of stem cells. Nevertheless, it is our hope that this Special Focus Issue may play a small part in highlighting a topic of strategic importance to the future success of regenerative medicine. Needless to say, I am indebted to all authors for their willingness to contribute to this project in such a timely manner and am enormously grateful to Theo Bond and Elena Conroy from the editorial office for their patience and dedication which has helped make such a daunting task so enjoyable.

\section{Financial \& competing interests disclosure}

The author has no relevant affiliations or financial involvement with any organization or entity with a financial interest in or financial conflict with the subject matter or materials discussed in the manuscript. This includes employment, consultancies, honoraria, stock ownership or options, expert testimony, grants or patents received or pending, or royalties.

No writing assistance was utilized in the production of this manuscript.

8 Vertès AA. The potential of cytotherapeutics in hematologic reconstitution and in the treatment and prophylaxis of graftversus-host disease. Chapter II: Emerging transformational cytotherapies. Regen. Med. 10(3), 345-373 (2015).

9 Consentius C, Reinke P, Volk HD. Immunogenicity of allogeneic mesenchymal stromal cells - what has been seen in vitro and in vivo? Regen. Med. 10(3), 305-315 (2015).

10 Or-Geva N, Reisner Y. Exercising 'veto’ power to make haploidentical hematopoietic stem cell transplantation a safe modality for induction of immune tolerance. Regen. Med. 10(3), 239-242 (2015).

11 Fairchild PJ, Leishman A, Sachamitr P, Telfer C, Hackett S, Davies TJ. Dendritic cells and pluripotency: unlikely allies in the pursuit of immunotherapy. Regen. Med. 10(3), 275-286 (2015).

12 Bredenkamp N, Jin X, Liu D, O’Neill KE, Manley N, Blackburn CB. Construction of a functional thymic microenvironment from pluripotent stem cells for the induction of central tolerance. Regen. Med. 10(3), 317-329 (2015). 